\title{
Útero Incandescente
}

\section{Incandescent Uterus}

\author{
O. Martínez Roca ${ }^{1} \quad$ M. L. Busto ${ }^{1}$
}

${ }^{1}$ Departamento de Resonancia Magnética, DIM Centros de Diagnóstico, Ramos Mejía, Buenos Aires, Argentina

Rev Argent Radiol 2018;82:193.

Address for correspondence O. Martínez Roca, MD, DIM Centros de Diagnóstico, Ramos Mejía, Buenos Aires, Argentina

(e-mail: omaroca80@hotmail.com).

Mujer de 42 años a quien se le realizó una resonancia magnética (RM) de abdomen y pelvis para el estudio de una lesión de aspecto quístico en ovario izquierdo. Antecedente: Planificación familiar con Dispositivo Intrauterino (DIU).

La - Fig. 1 corresponde a un corte de pelvis en secuencia ponderada en $\mathrm{T} 2$, plano axial, observándose una imagen

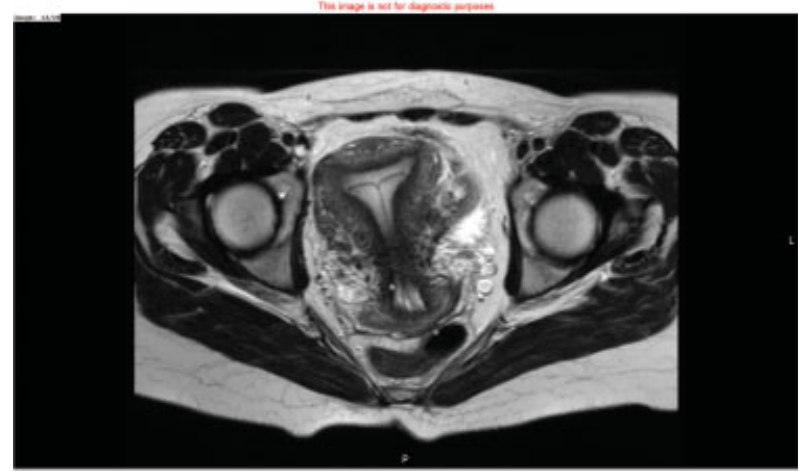

Fig. 1 Imagen en plano axial de RM de pelvis potenciada en T2, se observa dispositivo intrauterino que remeda una lámpara incandescente. similar al invento patentado por Thomas Alva Edison, en donde el contorno del útero remeda a la ampolla, el DIU al filamento e hilos conductores y el cervix al casquillo metálico, partes de una lámpara (bombilla) incandescente (-Fig. 2).

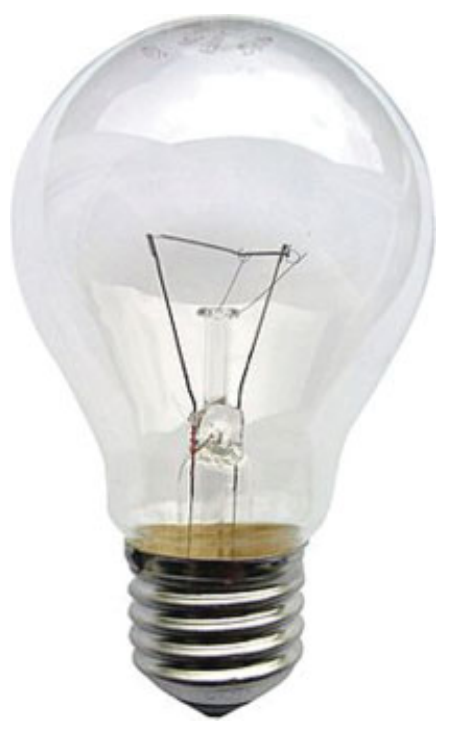

Fig. 2 Lámpara (Bombilla) Incandescente. received August 16, 2017 accepted September 2, 2017 published online July 18,2018
DOI https://doi.org/

10.1055/s-0038-1639496. ISSN 1852-9992.
Copyright $\odot$ 2019, Sociedad Argentina de Radiología. Publicado por Thieme Revinter Publicações Ltda., Rio de Janeiro, Brazil. Todos los derechos reservados.
License terms

(ㄷ) (i) $\ominus$ () 